\title{
Evaluation of Charcot Neuroarthropathy in Diabetic Foot Disease Patients at Tertiary Hospital
}

\author{
Ahmed M. A. Kensarah*, Nisar Haider Zaidi, Abdulhaleem Noorwali, Hager Aref, \\ Ahmed Mohammed Makki, Afaf Ghunaim, Wail Tashkandi, \\ Sara Mohammad Beayari, Adel Johari \\ Department of Surgery, Faculty of Medicine, King Abdulaziz University Hospital, King Abdulaziz University, \\ Jeddah, Saudi Arabia \\ Email: *amkensarah@yahoo.com,drnhzaidi@hotmail.com, anoorwali22@yahoo.com, \\ dr.hageraref@gmail.com,dr.ahmed.makki@gmail.com, afaf.ghunaim@gmail.com, \\ wail_tashkandi@yahoo.com, s.beayari@hotmail.com,dr_johari@hotmail.com
}

Received 14 April 2016; accepted 31 May 2016; published 3 June 2016

Copyright (C) 2016 by authors and Scientific Research Publishing Inc. This work is licensed under the Creative Commons Attribution International License (CC BY). http://creativecommons.org/licenses/by/4.0/

c) (†) Open Access

\section{Abstract}

Purpose: To evaluate Charcot neuroarthropathy in diabetic foot patients at tertiary hospital. Methods and Material: It is a retrospective study from 2005 to 2015 of Charcot foot patients in diabetic patients admitted in King Abdulaziz University Hospital, Jeddah, Saudi Arabia. Sixty-four patients were admitted as diabetic foot disease and were studied by reviewing patients records of demography, pain, discharge, duration of disease, duration and types of diabetes IDDM [Insulin Dependant Diabetes Mellitus] NIDDM [Non Insulin Dependent Diabetes Mellitus], history of trauma, peripheral vascular disease, obesity, hypertension, co-morbid conditions, previous surgery, involvement of fore foot/midfoot/hindfoot, deformity, ulcer and treatment like casts, offloading devices, pharmacological like biphosphonates, debridement, osteotomy, arthrodesis, exostectomy, and amputation. Results: Majority of patients were males (81.2\%). Mean age was 61.75 years. Pain was reported in $25 \%$ of patients, numbness in $12.5 \%$, foot deformity in $23.4 \%$, pus discharge in $\mathbf{7 3 . 4 \%}$, difficulty in walking in $\mathbf{1 2 . 5 \%}$, and $\mathbf{1 0 . 9 \%}$ had history of trauma. Majority of patients were NIDDM 68.8\%, IDDM 31.3\%, $(62.5 \%$ had DM more than 10 years and $36.9 \%$ had DM less than 10 years), controlled DM in $21.9 \%$ and uncontrolled DM in $73.4 \%$, nephropathy in $46.3 \%$, neuropathy in $59.4 \%$, retinopathy in $40.6 \%$, cardiomyopathy in $48.4 \%$ and vasculopathy in $56.3 \%$. Charcot arthropathy was in $\mathbf{2 8 . 1 \%}$ of cases and forefoot was involved in $\mathbf{6 5 . 5 \%}$, midfoot in $4.7 \%$ and hindfoot/ankle in $\mathbf{2 1 . 9 \%}$. It was forefoot which was mainly involved in Charcot joint disease. It was demonstrated by $X$-rays which showed subluxation in $40.6 \%$, dislocation in $54.7 \%$, disorganized foot joints in $42.2 \%$, bone resorption in $23.4 \%$, osteomyelitis in $14.1 \%$, fractures in $50 \%$, joint

${ }^{*}$ Corresponding author.

How to cite this paper: Kensarah, A.M.A., Zaidi, N.H., Noorwali, A., Aref, H., Makki, A.M., Ghunaim, A., Tashkandi, W., Beayari, S.M. and Johari, A. (2016) Evaluation of Charcot Neuroarthropathy in Diabetic Foot Disease Patients at Tertiary Hospital. Surgical Science, 7, 250-257. http://dx.doi.org/10.4236/ss.2016.76036 
collapse in $39.1 \%$ and destruction of articular surfaces in $37.5 \%$. Debridement was done in $25 \%$ of cases while $75 \%$ of patients underwent some sort of amputation. $14.1 \%$ of patients underwent above knee amputation, $10.9 \%$ below knee amputation, $10.9 \%$ transmetatarsal and $39.1 \%$ toe amputation. Debridement and amputation were the main treatment offered. Conclusions: Diabetic patients with Charcot joint disease pose great challenge in management. Emphasis should be given for early detection, investigations and prompt treatment. Treatment should be tailored according to stage of disease and patient occupation.

\title{
Keywords
}

\author{
Charcots, Diabetes, Arthropathy, Diabetic Foot, Prevalence
}

\section{Introduction}

Charcot foot disease is commonly associated with diabetic patients. It was first described by J.M. Charcot in patient of tabesdorsalis [1]. Long standing diabetes is one of causative factors in the development of Charcot joint disease. Charcot Osteoarthropathy [COA] is a debilitating disease and sometimes can be limb threatening. It affects joints, bones, and soft tissue of foot and ankle. Various factors like diabetic neuropathy, trauma, and metabolic abnormalities of bone result in inflammatory response which leads to bone destruction, joint destruction, dislocation and deformity [2]. Its prevalence in diabetic patients is $0.4 \%$ to $13 \%$ [3] [4]. Other than diabetes rheumatoid arthritis, trauma, multiple sclerosis, leprosy, poliomyelitis, alcohol abuse, syringomyelia, heavy metal poisoning, and congenital neuropathies also contribute to the development of Charcot osteoarthropathy [5] [6]. Prevalence of Charcot foot disease is increasing which may be due to new imaging which results in increase in diagnosis [7]. It is common in fifth and sixth decades and more than $80 \%$ of them had diabetes for more than 10 years [8]. It is commonly unilateral but it may be bilateral in up to $25 \%$ of cases [9]. It presents as swollen, red, hot, and painless foot usually in diabetic patient which may clinch the diagnosis. However, it must be distinguished from trauma, cellulitis, sprain, acute gout, deep vein thrombosis and osteomyelitis [10]. Treatment starts with offloading which is required to prevent progression of disease, while surgery is needed in chronic cases with joint instability or deformity [11]. We present our experience in treating Charcot disease at our tertiary hospital.

\section{Methods}

It is a retrospective study from 2005 to 2015 of Charcot foot patients in diabetic patients admitted in King Abdulaziz University Hospital, Jeddah, Saudi Arabia. Sixty four patients were admitted as diabetic foot disease and were studied. Patients admitted for diabetic foot disease in hospital were studied for Charcot joint disease. Collection of data done by reviewing patients files, OPD visits, OR notes and inpatients records. Analysis was done by noting age, sex, nationality, pain, discharge, duration of disease, Duration and types of diabetes IDDM, NIDDM, history of trauma, peripheral vascular disease, obesity, hypertension, co-morbid conditions, previous surgery, involvement of fore foot/midfoot/hindfoot, deformity, ulcer and treatment like casts, offloading devices, pharmacological like biphosphonates, debridement, osteotomy, arthrodesis, exostectomy, and amputation.

\section{Results}

Majority of patients were males $81.2 \%$ and females $18.8 \%$. Mean age was 61.75 years. Pain was reported by $25 \%$ of patients, numbness by $12.5 \%$, foot deformity by $23.4 \%$, discharge by $73.4 \%$, difficulty in walking by $12.5 \%$, and $10.9 \%$ had history of trauma. Most common complaints was discharge from foot wound. Majority of patients were NIDDM 68.8\%, IDDM 31.3\%, 62.5\% had DM more than 10 years and 36.9\% had DM less than 10 years, controlled DM in $21.9 \%$ and uncontrolled DM in $73.4 \%$. Charcot joint disease was prevalent in patients who had diabetes for longer duration. Patients who are controlling their diabetes developed Charcot joint disease. These patients developed Nephropathy in $46.3 \%$, neuropathy in $59.4 \%$, retinopathy in $40.6 \%$, cardiomyopathy in $48.4 \%$ and vasculopathy in $56.3 \%$. This is the sequel of long standing diabetes mellitus disease. 
Co-morbidities had a role in development of Charcot disease Associated co-morbidities were obesity in $10.9 \%$, hypertension in $83.8 \%$, dyslipidemia in $31.3 \%$, hypothyroidism in $14.1 \%$, immunosuppression in $3.1 \%$ of cases, arrhythmia in $3.1 \%$ and anemia in $84.4 \%$. Most associated co-morbidity was hypertension. Charcot arthropathy was in $28.1 \%$ of cases and forefoot was involved in $65.5 \%$, midfoot in $4.7 \%$ and hindfoot/ankle in $21.9 \%$. Forefoot involvement was found in majority of our patients. X-rays showed subluxation in $40.6 \%$, dislocation in $54.7 \%$, disorganized foot joints in $42.2 \%$, bone resorption in $23.4 \%$, osteomyelitis in $14.1 \%$, fractures in 50\%, joint collapse in s39.15 and destruction of articular surfaces in $37.5 \%$. Common pathology in our patients were subluxation and dislocation in forfoot joints.

Debridement was done in $25 \%$ of cases while $75 \%$ of patients underwent some sort of amputation. $14.1 \%$ of patients underwent above knee amputation, $10.9 \%$ below knee amputation, $10.9 \%$ transmetatarsal and $39.1 \%$ toe amputation (Figures 1-14).

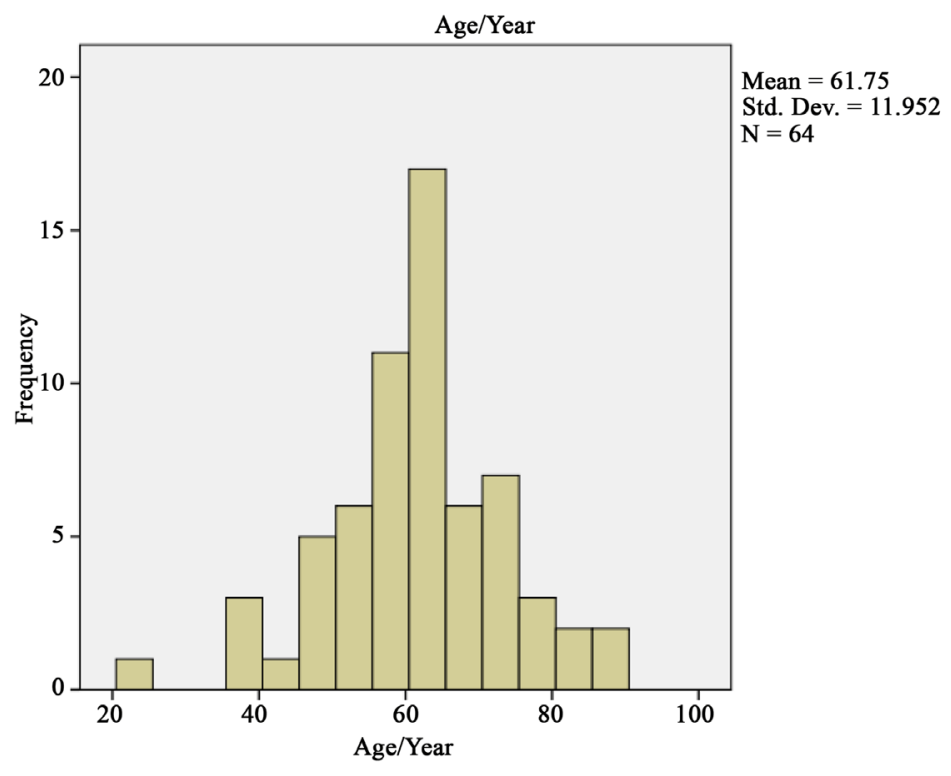

Figure 1. Age distribution.



Figure 2. Complaints.

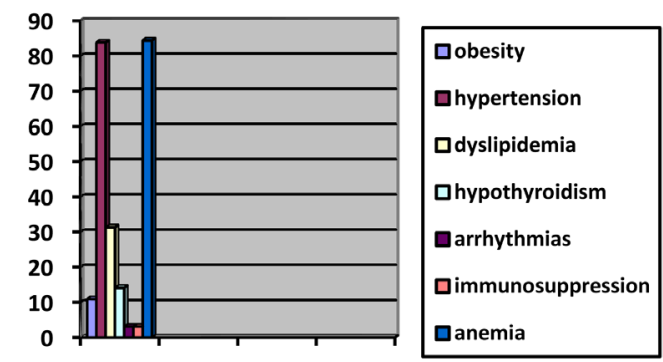

Figure 3. Co-morbidities. 


\begin{tabular}{cc}
\hline Diabetes Details & Percentage \\
\hline IDDM & 68.8 \\
NIDDM & 31.3 \\
More than 10 yrs & 62.5 \\
Less than 10 yrs & 36.9 \\
Controlled & 21.9 \\
Not controlled & 73.4 \\
Nephropathy & 46.3 \\
Neuropathy & 59.4 \\
Retinopathy & 40.6 \\
Cardiomyopathy & 48.4 \\
Vasculopathy & 56.3 \\
\hline
\end{tabular}

Figure 4. Diabetes details.



Figure 5. Co-morbidities.

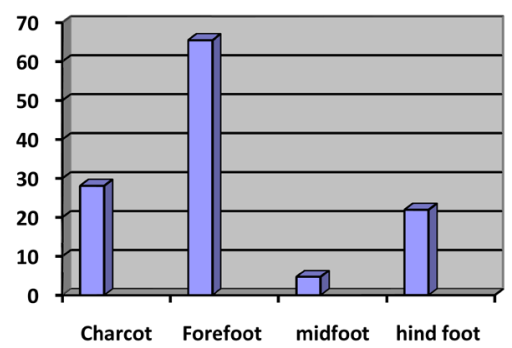

Figure 6. Physical findings.

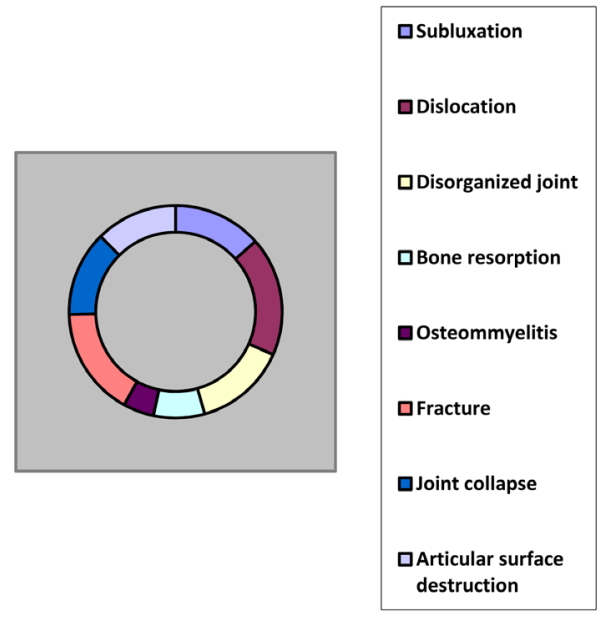

Figure 7. X-ray findings. 


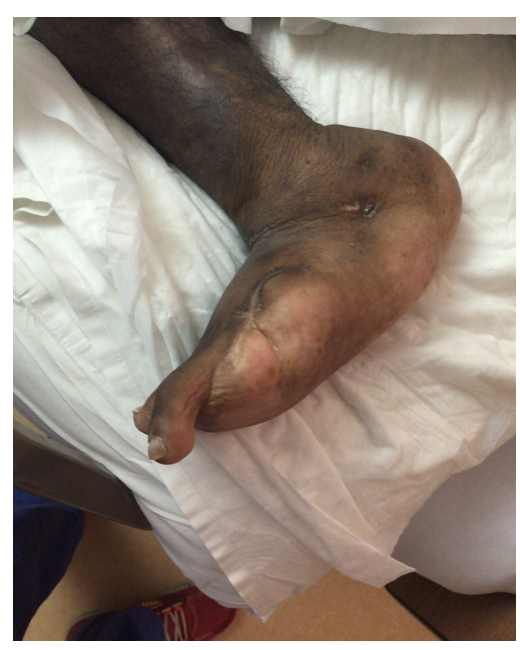

Figure 8. Charcot foot.

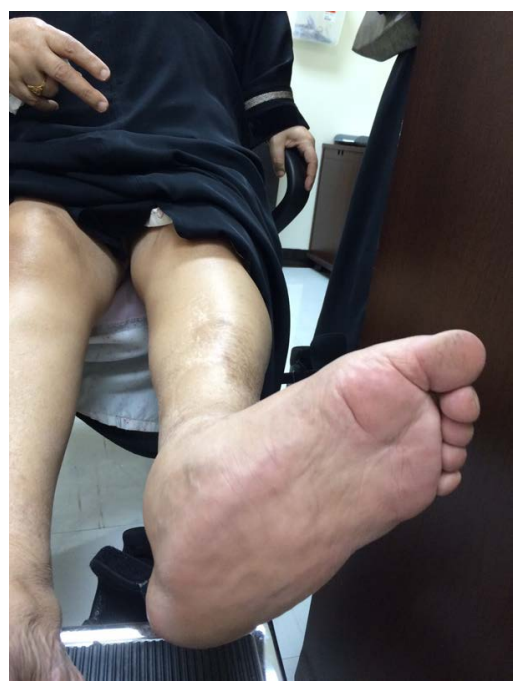

Figure 9. Charcot foot.

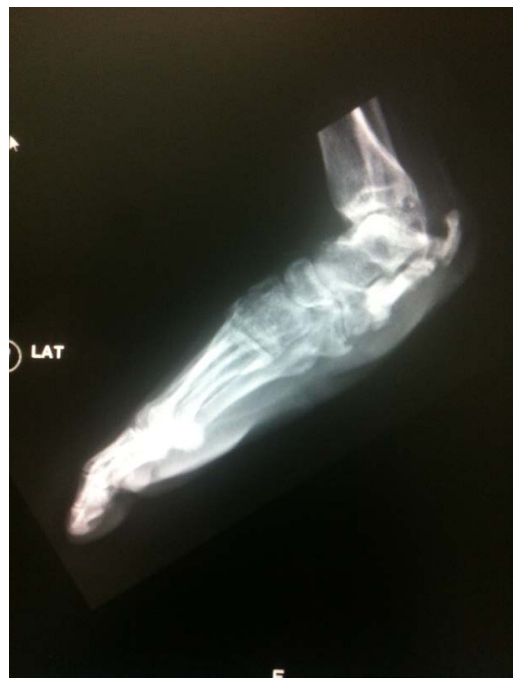

Figure 10. Rocker bottom foot deformity. 


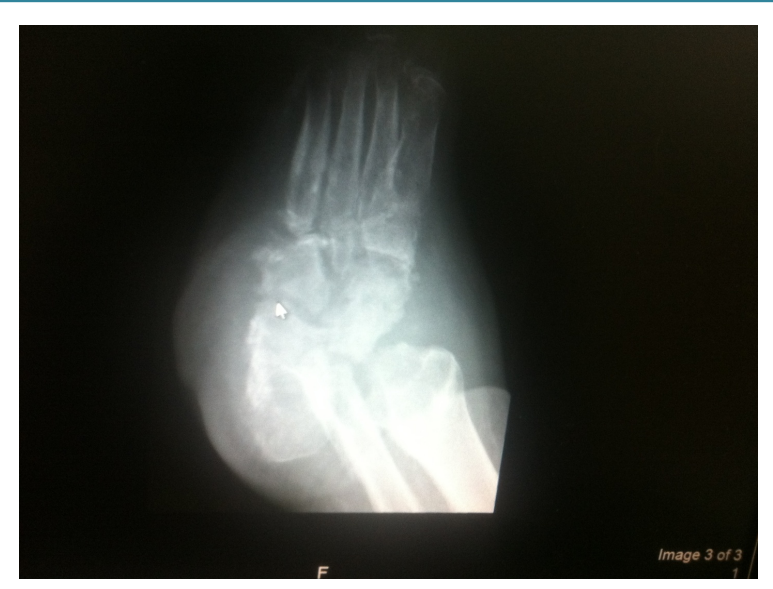

Figure 11. Hind foot deformity.

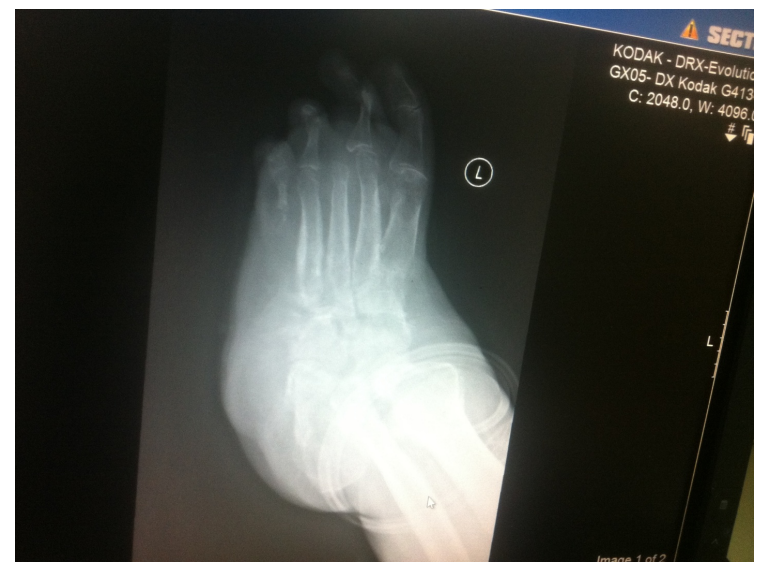

Figure 12. Hind foot deformity.

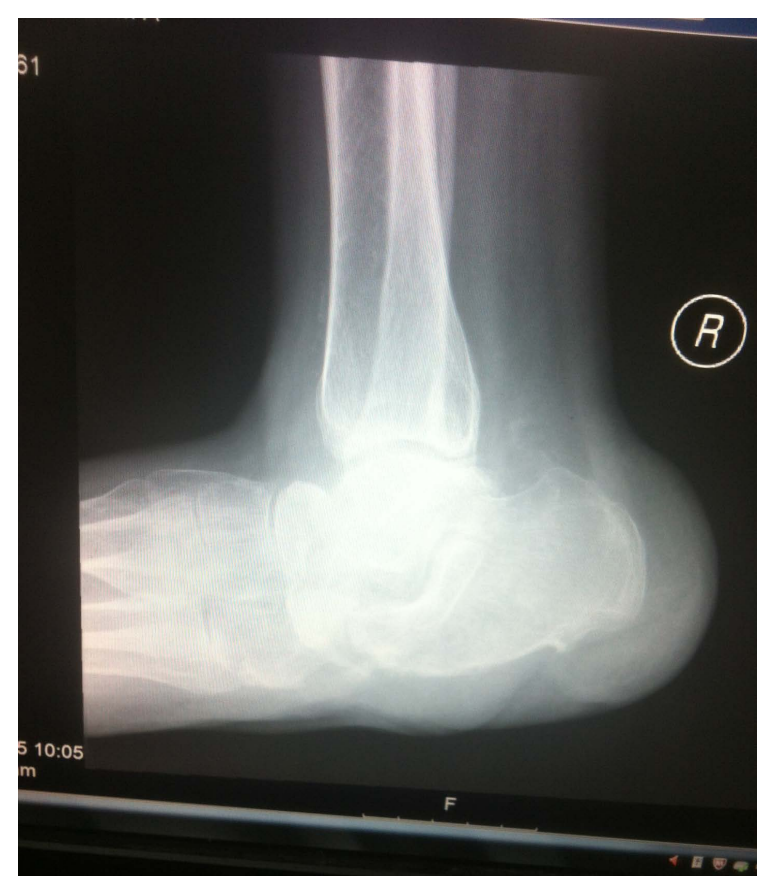

Figure 13. Calcaneo-taler angle deformity. 


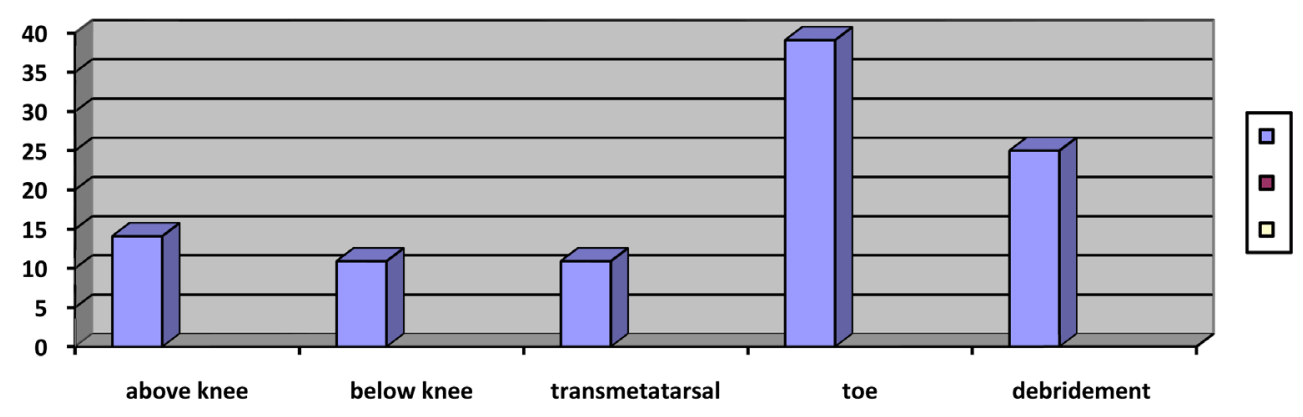

Figure 14. Surgical treatment, level of amputation.

\section{Discussion}

Pathogenesis of Charcot foot disease is multifactorial. In diabetes polyneuropathy is one of initial event in Charcot osteopathy. Sensory neuropathy results in decreased sensations and repeated microtrauma results in hyperemia and ultimately destruction of joints. Motor neuropathy causes decreased strength of intrinsic and extrinsic muscles resulting in deformity which further causing abnormal plantar pressures and abnormal collagen formation [12]. Autonomic neuropathy leads to increased perfusion and increased osteoclast activity resulting in osteopenia and pathologic fractures [13]. Incidence is equal in both sexes. Patients who are at high risk of developing Charcot arthropathy are poorly controlled diabetes more than 10 years, neuropathy and trauma [12]. Charcot neuroarthropathy is classified into many groups to tailor treatment. Eichenholtz classification of neuropathy divides into three stages, 1 -development where subluxation, osteolysis and fracture occur, stage-2 coalescence where resorption of debris and fusion of fracture occur and stage-3 where healing and hypertrophic bone formation occur [14]. Sella and Barette introduced five stages, stage-0 has pain, erythema, oedema, warm foot. Stage-1 osteopenia, erosions, diastasis, stage-2 subluxation, stage-3 dislocationand joint destruction and stage-4 which is characterized by healing and hypertrophic bone formation [15]. Sanders-Frykberg classified anatomically into five patterns, 1-forefoot, 2-Tarsometatarsal joint, 3-Talonavicular, calcaneocuboid and naviculocuneiform, 4-ankle joint and 5-calcaneus [12].

Mean age of our patient was 61.4 years which is near similar to studies of Sanders et al. where it was mid fiftees [12] and 63 years in study of Min et al. [16]. Charcot foot disease is commonly found in elder population. In our study majority of patients were males $81.2 \%$, and females $18.8 \%$ while Min et al. reported males $97.1 \%$ [16]. This again confirms the fact that diabetic foot disease is a disease of middle age and Charcot neuroarthropathy develops in long standing diabetic foot disease. Males are commonly involved in Charcot disease as they are commonly do the manual work and spend long time in doing physical work related to their profession. Twenty five percent patients complained of foot pain in our study while Baglioni, Botek, and Petrova et al. reported pain in less than 50\% of cases [17]-[19]. Since patients with Charcot neuroarthropathy have neuropathy so less number of our patient reported pain. $62.5 \%$ of our patients had diabetes for more than 10 years which is similar to studies of Leung et al. and Samann et al. [4] [20]. X-rays were used to diagnose bony changes in Charcot patients. Initial X-rays were normal and patients had only soft tissue deformity. $28.1 \%$ of diabetic patients had Charcot foot disease in our patients which is quite high percentage. Forefoot was involved in majority of our patients 65\% followed by hind foot and midfoot. Offloading was non operative management and commonly it was foot wear. The gold standard of off-loading is the total contact cast [11] [21]. Arthrodesis of joints is another option for treatment. Surgery in the form of debridement and amputation was offered in majority of our patients. Majority had toe amputation followed by below knee amputation.

\section{Conclusion}

Diabetic patients with Charcot joint disease pose great challenge in management. Emphasis should be given for early detection, investigations and prompt treatment. Treatment should be tailored according to stage of disease and patient occupation.

\section{References}

[1] Trepman, E., Nihal, A. and Pinzur, M.S. (2005) Current Topics Review: Charcot Neuroarthropathy of the Foot and 
Ankle. Foot \& Ankle International, 26, 46-63.

[2] Frykberg, R.G., Zgonis, T., Armstrong, D.G., Driver, V.R., Giurini, J.M., Kravitz, S.R., Landsman, A.S., Lavery, L.A., Moore, C., Schuberth, J.M., Wukich, D.K., Anderson, C. and Vanore, J.V. (2006) Diabetic Foot Disorders: A Clinical Practice Guideline. Journal of Foot and Ankle Surgery, 45, S1-S66. http://dx.doi.org/10.1016/S1067-2516(07)60001-5

[3] Frykberg, R.G. and Belczyk, R. (2008) Epidemiology of the Charcot Foot. Clinics in Podiatric Medicine and Surgery, 25, 17-28. http://dx.doi.org/10.1016/j.cpm.2007.10.001

[4] Leung, H.B., Ho, Y.C. and Wong, W.C. (2009) Charcot Foot in Hong Kong Chinese Diabetic Population. Hong Kong Medical Journal, 15, 191-195.

[5] Gupta, R. (1993) A Short History of Neuropathic Arthropathy. Clinical Orthopaedics and Related Research, 296, 4349. http://dx.doi.org/10.1097/00003086-199311000-00009

[6] Wukich, D.K. and Sung, W. (2009) Charcot Arthropathy of the Foot and Ankle: Modern Concepts and Management Review. Journal of Diabetes and Its Complications, 23, 409-426. http://dx.doi.org/10.1016/j.jdiacomp.2008.09.004

[7] Rajbhandari, S.M., Jenkins, R.C., Davies, C. and Tesfaye, S. (2002) Charcotneuroarthropathy in Diabetes Mellitus. Diabetologia, 45, 1085-1096. http://dx.doi.org/10.1007/s00125-002-0885-7

[8] Cofield, R.H., Morrison, M.J. and Beabout, J.W. (1983) Diabetic Neuroarthropathy in the Foot: Patient Characteristics and Patterns of Radiographic Change. Foot Ankle, 4, 15-22. http://dx.doi.org/10.1177/107110078300400104

[9] Frykberg, R.G. (2000) Charcot Foot. In: Boulton, A.J.M., Connor, H. and Cavanagh, P.R., Eds., The Foot in Diabetes, John Wiley Sons, Chichester, 235-260. http://dx.doi.org/10.1002/0470846399.ch17

[10] Chantelau, E. (2005) The Perils of Procrastination: Effects of Early vs. Delayed Detection and Treatment of Incipient Charcot Fracture. Diabetic Medicine, 22, 1707-1712. http://dx.doi.org/10.1111/j.1464-5491.2005.01677.x

[11] Stefansky, S.A. and Rosenblum, B.I. (2005) The Charcot Foot: A Clinical Challenge. International Journal of Lower Extremity Wounds, 4, 183-187. http://dx.doi.org/10.1177/1534734605280187

[12] Sanders, L.J. and Frykberg, R.G. (1993) Charcot Foot. In: Levin, M.E., O’Neal, L.W. and Bowker, J.H., Eds., The Diabetic Foot, Mosby, St. Louis, 149-180.

[13] Armstrong, D.G., Todd, W.F., Lavery, L.A., Harkless, L.B. and Bushman, T.R. (1997) The Natural History of Acute Charcot's Arthropathy in a Diabetic Foot Specialty Clinic. Journal of the American Podiatric Medical Association, 87, 272-278. http://dx.doi.org/10.7547/87507315-87-6-272

[14] Yu, G.V. and Hudson, J.R. (2002) Evaluation and Treatment of Stage 0 Charcot's Neuroarthropathy of the Foot and Ankle. Journal of the American Podiatric Medical Association, 92, 210-220. http://dx.doi.org/10.7547/87507315-92-4-210

[15] Armstrong, D.G. and Peters, E.J.G. (2002) Charcot's Arthropathy of the Foot. Journal of the American Podiatric Medical Association, 92, 390-394. http://dx.doi.org/10.7547/87507315-92-7-390

[16] Min, W.S., Todd, A.L., Rodney, M.S., Fryberg, R.G. and Elly, B.M. (2009) Mortality Risk of Charcot Arthropathy Compared with That of Diabetic Foot Ulcerand Diabetes Alone. Diabetes Care, 32, 816-821. http://dx.doi.org/10.2337/dc08-1695

[17] Baglioni, P., Malik, M. and Okosieme, O.E. (2012) Acute Charcot Foot. BMJ, 344, 1-4. http://dx.doi.org/10.1136/bmj.e1397

[18] Botek, G., Anderson, M.A. and Taylor, R. (2010) Charcot Neuroarthropathy: An Often Overlooked Complication of Diabetes. Cleveland Clinic Journal of Medicine, 77, 593-599. http://dx.doi.org/10.3949/ccjm.77a.09163

[19] Petrova, N.L. and Edmonds, M.E. (2008) Charcot Neuro-Osteoarthropathy—Current Standards. Diabetes/Metabolism Research and Reviews, 24, 58-61. http://dx.doi.org/10.1002/dmrr.846

[20] Samann, A., Pofahl, S., Lehmann, T., Voigt, B., Victor, S., Moller, F., Muller, U.A. and Wolf, G. (2012) Diabetic Nephropathy but Not HbA1c Is Predictive for Frequent Complications of Charcot Feet-Long-Term Follow-Up of 164 Consecutive Patients with 195 Acute Charcot Feet. Experimental and Clinical Endocrinology \& Diabetes, 120, 335339. http://dx.doi.org/10.1055/s-0031-1299705

[21] van der Ven, A., Chapman, C.B. and Bowker, J.H. (2009) Charcot Neuroarthropathy of the Foot and Ankle. Journal of the American Academy of Orthopaedic Surgeons, 17, 562-571. http://dx.doi.org/10.5435/00124635-200909000-00003 